\title{
O BEST-SELLER NA REVALORIZAÇÃO DE SENTIDOS: "HARRY POTTER" E O TEMA DA CRIANÇA IMAGINAL
}

\author{
Gisela Cristina Ribeiro Silva*
}

\begin{abstract}
RESUMO: O tema da criança e, para nós, dos adolescentes é cada vez mais um assunto de discussão em que são abordadas várias análises e/ou problemáticas. Considerando uma das questões primordiais da existência da adolescência, que é a do adolescente como ser imaginal, a questão que se coloca prende-se com a seleção e posterior anexação das leituras bestselerianas por leitores tão jovens. Como justificar esse apego a livros de tão numerosas páginas? A resposta não é de todo difícil se compreendermos como protagonistas, no relacionamento livro/leitor, factores que apontam para a importância polifónica da obra; a problemática da "intentio lectoris" (Eco, 1990) e, finalmente, mas não por esta ordem de ideias, a noção de vacuidade à qual a criação de qualquer obra literária deve obedecer. Considerando os itens em destaque, pretende-se tão-só, a partir da saga Harry Potter, compreender a importância de determinadas imagens e aceder às suas significaçōes mítico-simbólicas. Construindo-se num todo a história do Eu-leitor imaginal, portador de qualidades e reminiscências arquetipais, serão expostas ideias conducentes à corporização do herói nas relaçôes de identidade/alteridade.
\end{abstract}

Palavras-chave: Criança imaginal. "Intentio lectoris". Best-sellers. Identidade e alteridade.

Doutora em Ciências da Educação e membro do Centro de Investigação em Estudos da Criança da Universidade do Minho (Portugal).E-mail: giselasilva3@gmail.com 
O best-seller na revalorização de sentidos: "Harry Potter" e o tema da criança imaginal

THE BEST-SELLER IN THE UPGRADING OF SENSES:

"Harry Potter" and the IMAGINAL ChILd ISSUE

ABSTRACT: The child, and for us, the adolescent issue, is increasingly a subject of discussion in which various analysis/ problematics are discussed. Considering one of the key matters: the adolescent's existence, that is the imaginal adolescent, a question is raised about the selection and subsequent annexation of bestseller readings by such young readers. How to explain this commitment to books with so many pages? It is not difficult to understand if we notice that the main actors in this relationship between book/reader, point to the importance of polyphonic works, the problem of "intentio lectoris" (Eco, 1990). Last but not least, the concept of emptiness to which the creation of any literary work must comply. Whereas the items in focus, we intend to have the Harry Potter's books as basis in order to understand the importance of the access to certain images and their mythical-symbolic meanings. Building itself in as a whole in the history of the I-imaginal reader, with reminiscences of qualities and archetypes will expose ideas of the leading hero in the embodiment of the relations between identity/alterity.

Key words: Imaginal child. "Intentio lectoris". Best-sellers. Identity and alterity.

\section{Introdução}

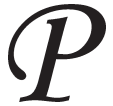

reocupados com os ainda baixos níveis de literacia e oraria, que só pelo fomento do gosto pela leitura e pela escrita poderão ser colmatados, temos estado atentos a diversos planos de intervenção no âmbito da educação implementados em alguns países da Europa, dos Estados Unidos da América e no Brasil. Tal permite-nos afirmar que, mais do que nunca, é necessário atentar nos objetivos matriciais da maioria desses programas e participar ativamente nestes tempos de mudança que valorizam um ensino e aprendizagem da língua sustentados nos programas de leitura fundamentados na literatura (Sloan, 1999; Yopp \& Yopp, 2001). E se em 2006 afirmávamos ser "urgente repensar a selecção de um cânone literário para a escola que motiv[asse] os alunos para a leitura" (Silva, 2006, p. 35), hoje afirmamos, ainda mais convictos, que é igualmente urgente motivar os docentes a usar o texto literário da literatura 
de massas ou de best-seller de forma integral para "agarrar" os jovens que ainda não se comprometem com o ato leitor.

Relativamente a esta literatura, acrescentaríamos o que Aguiar (1998, p. 393) refere ao reflectir sobre a importância da mutabilidade dos géneros literários, que "desempenham (...) um importante papel na organização e na transformação do sistema literário" e que tanto podem desaparecer ou persistir ao longo dos tempos, mediante "as modificações sociais, culturais, ideológicas e políticas", sobretudo se estes "alter[am] a constituição do público leitor" ( $p$. 395). No que diz respeito ao nosso trabalho, esta reflexão obriga-nos a pensar, por um lado, na existência de outra literatura juvenil contemporânea que tem, pelo género que integra, obrigado à constatação de uma literatura juvenil anexada e que denominamos de "nova literatura" de potencial receção juvenil.

É, no nosso caso, o género fantástico, ou fantástico-maravilhoso que se viu reavivado na nossa cultura literária, com o inegável sucesso editorial da saga Harry Potter (1997-2007), de Joanne K. Rowling, dando-se um novo élan à nossa literatura de potencial receção juvenil. As livrarias do mundo inteiro foram invadidas por um género literário que, se para alguns era já do domínio comum, em Portugal era praticamente desconhecido. Logo, os jovens leitores viram-se envolvidos na leitura da participação, da curiosidade e da exploração de sentidos e temas. Por isso, pensamos ainda que o reconhecimento de Harry Potter como a grande obra impulsionadora, a nível mundial, de um género literário já esquecido e/ou, na altura para alguns pré-adolescentes e adolescentes até desconhecido, deve ser motivo de reflexão no que se reporta às obras que se lhe seguiram. O facto de se constatar que imensas obras do mesmo género e qualidade literária têm, desde há quase uma década, sido as obras de eleição para os jovens reforça a importância desta "nova literatura” no acervo literário destinado maioritariamente aos jovens. Não podemos esquecer que é nelas que a magia de um imaginário infantil, pertencente ao género fantástico maravilhoso, se deixa ler de forma tão apetecida, cumprindo-se a desejada "intentio lectoris" (Eco, 1990).

Acreditamos que, portanto, quer em contexto escolar ou familiar, quer nos chamados momentos de lazer, este leitor (também ele realizador da palavra escrita) será cada vez mais o nosso desejado leitor "renascido", pois ele estará em contacto com textos portadores de significados e mensagens que coexistem, tanto com a sua capacidade imaginante, 
O best-seller na revalorização de sentidos: "Harry Potter" e o tema da criança imaginal

como com as suas identidade/alteridade. Não querendo debruçar-nos sobre a problemática relativa à existência ou não da literatura infanto-juvenil enquanto literatura, ${ }^{2}$ gostaríamos de suscitar uma discussão que nos permitisse, ao longo desta exposição, aceder à noção de literatura de potencial receção juvenil, ${ }^{3}$ enquanto literatura anexada, e tentar refletir sobre o facto de esta se oferecer ao jovem leitor como objecto de fruição e, simultaneamente, de aprendizagem.

A literatura de massas ou "bestseleriana" de potencial receção Juvenil e a promoção leitora no reencontro do Eu imaginal

Tendo em conta o que acabamos de referir - o facto de uma área, cada vez mais representativa (desde inícios do século XXI), da produção literária em língua portuguesa (ou estrangeira, traduzida) ser constituída pela literatura de potencial receção juvenil contemporânea do fantástico (que, muitas vezes, se baliza entre o maravilhoso e o fantástico $\left.{ }^{4}\right)$, que apelidamos de "nova literatura", e que estudiosos de referência denominam de "high fantasy"; o facto dessa literatura se destinar maioritariamente a um potencial leitor cuja faixa etária se baliza entre os dez e quinze anos, aproximadamente; a relevância em se destacar a responsabilidade, a nosso ver, acrescida da literatura de potencial receção juvenil na formação de um leitor, quantas vezes fugaz e demasiado comprometido com outras literacias e ainda o facto desta se flanquear por uma permuta de ideias, valores, situações e circunstâncias com um leitor em contínua transformação e demanda (não fosse a adolescência a idade da contestação por natureza), - acreditamos ser urgente observar esta literatura juvenil com outros olhos.

Assim sendo, e reconhecendo que o texto literário é o instrumento de trabalho por excelência, pois, como o refere Azevedo (2002, p. 307), este é "concebido como um modelo de exploração e de experimentação inovadora das inúmeras possibilidades do sistema [e] possibilita ao aluno tomar consciência da natureza e mecanismos de funcionamento [do] complexo e refinado sistema semiótico de que o homem dispõe", consideramos a importância destes textos da "nova literatura" de potencial receção juvenil no desenvolvimento psicossociológico e pedagógico dos pré-adolescentes e adolescentes. Consideramos ainda que cabe aos professores, essencialmente de Português, serem efetivos mediadores de 
leitura, pois o pré e/ou adolescente-discente (ser imaginal por excelência) precisa ser orientado e ensinado a saber agir perante um texto literário que exige a sua contínua implicação na criação, multiplicação e revalorização de significados, temas e símbolos, numa perceção integradora do mundo.

A adoção (por nós defendida) de um estudo/aplicação do imaginário ao nível da leitura/compreensão de obras contemporâneas de potencial receção juvenil obriga-nos a insistir no facto de serem as obras desta "nova literatura" que fazem ler os adolescentes, até os mais avessos à leitura e da escrita. Tal é fácil de provar quando deixamos que essas leituras sejam convidadas à participação e ao diálogo dentro das nossas salas de aulas, bibliotecas e convívios entre a escola e a comunidade/família. São, pois, estas obras (quantas vezes injustamente marginalizadas e qualificadas de "literatura menor" ou "paraliteratura") que, lidas e orientadas segundo os princípios promotores da leitura e da escrita, solicitam e oferecem o tão desejado manancial de possibilidades intertextuais, assegurando a desejada polifonia do discurso e os exercícios de reflexão e recreação. Enriquecido pela hermenêutica do imaginário, o pré-adolescente e/ou o adolescente testemunha o momento da leitura como um ato de entrega, de fruição e de aprendizagem. Tal é capaz de lhe permitir o debate sobre questôes históricas, socioculturais e do seu interesse mais pessoal (como, por exemplo, solicitações a questôes existenciais) na compreensão de determinadas mensagens e possíveis leituras mítico-simbólicas. Validamos, então, na leitura do imaginário, uma leitura global do texto, destacando-se enfaticamente o seu caráter polissémico e pluri-isotópico de abertura ao Outro e a outras realidades, o que permite ao seu interlocutor “(...) experimentar a força ilocutiva e o poder perlocutivo dos vocábulos, sensibilizando-o para a coloração afetiva e imagética das palavras, de modo a reconhecer e a mobilizar, em discurso autónomo, os seus valores na expressão singular de emoções ou de ideias" (Azevedo, 2006, p. 21).

$\mathrm{Na}$ gestão deste binómio (leitor/texto), salientamos o uso apropriado de um imaginário construtor, onde são chamados ao palco os demais interesses, emoções e sensibilidades estéticas do leitor, capazes de facultarem os tão desejados momentos de verdadeira fruição entre este e as personagens da obra (cumprindo-se momentos de identidade com o herói da história), ou ainda situações literácitas geradoras de surpreendentes 
O best-seller na revalorização de sentidos: "Harry Potter" e o tema da criança imaginal

manifestações mediadoras entre diferentes grupos sociais, culturas e gerações.

\section{A cooperação do sujeito-leitor na leitura mítico-simbólica}

Propomo-nos, neste texto, acrescentar às investigações já realizadas a reflexão sobre algumas das possibilidades de leitura mítico-simbólicas relativas à saga Harry Potter (Rowling, 1997-2007). Salientamos que, nesta saga, como em outras obras de igual valor literário, a preocupação autoral centrou-se na transmissão de um conjunto de ideologias e valores tidos atualmente como indispensáveis na afirmação da cidadania crítica e reflexiva do ser imaginante, o que só por si dignifica a obra.

Sabemos, pois, que se a cooperação do sujeito-leitor com o texto não se puder manifestar, o próprio enunciado, na sua globalidade, terá perdido o seu significado e a noção de vacuidade, na perspectiva do "preenchimento" do texto (pelo seu valor literário polifónico), não se terá cumprido. Isto é, durante a leitura, não se terá produzido "um trabalho de transformação do texto" (Iser, 1997, p. 13), que acontece quer pela vontade do leitor descodificador, quer pela dinâmica do texto que se quer dar a ler em toda a sua alteridade pluri-isotópica. Tal situação obriganos a destacar a importância, atribuída por Umberto Eco, à problemática da "intentio lectoris" (Eco, 1990).

A propósito dos "dois modelos de interpretação" (Eco, op. cit., p. 19-112) propostos no capítulo "Apontamentos sobre a semiótica da receção", Eco debruça-se sobre a problemática da "intentio lectoris" e afirma, entre muitas aceções, que o verdadeiro leitor é aquele que assume o texto como um "universo aberto que compreende que o verdadeiro significado de um texto é o seu vácuo" (p. 56-62). Esta asserção obriga-nos a abordar a noção do sujeito imaginal destacando-se a importância de estudos $^{6}$ feitos na intenção de se recuperar as qualidades arquetipais da criança (aqui também do adolescente), tendo o educador/mediador um papel decisivo no processo de concomitância a estabelecer entre a criança real (que tem as suas recordaçôes) e a infância imaginal (que tem as suas reminiscências arquetipais). Filipe Alberto Araújo e Joaquim Machado Araújo defendem, ainda, que a necessidade desta "re-união" entre a criança real e a infância imaginal 
(...) implica a afirmação de que a criança interior, enquanto faceta da alma humana, deve irrigar a criança real e levanta a questão de saber de que modo se deveria educar a criança para que esta unidade seja actuante e não meramente um apelo, ainda que bem-intencionado. (Araújo \& Araújo, 2008)

Propomos, assim, tal como os autores, um empenho por parte do educador/mediador no sentido de adotar a noção da "criança eterna" que existe no adulto (idem, ibid.), e que mais não é do que ousar "ir-maislonge de si e do Outro" (idem, ibid.). Isto é, originar uma aproximação infalível entre os sujeitos implicados na aprendizagem, tornando mútuas as intençõos do educador e do educando, para que se cumpra o real sentido da educabilidade, onde o educador, através da sua atuação, conduz o jovem educando à noção da participação/interacção com o seu circundante. $^{7}$

\section{Harry Potter: o desejo de ler a "infância imaginal"}

Ao querermos fazer valer a imagem "da criança arquetipal que a criança real transporta dentro de si” (Araújo \& Araújo, 2008), consideramos a saga Harry Potter um construto semiótico, cuja dimensão míticosimbólico é densa, dado que o seu destinatário leitor é ainda muito jovem. As imagens, por sua vez, são valiosas para a leitura adequada do imaginário, pois nos permitem aceder ao tema do herói ${ }^{8}$ e, por conseguinte, à sua aventura, assegurada pelas temáticas ligadas ao seu chamamento, à sua iniciação, ao objecto da sua demanda e ao seu regresso vitorioso. Logo, o desejo de ler a "infância imaginal" leva-nos a considerar a importância da obra, quer pelas vivências do herói, quer pelos diferentes mitos do regressus ad originem que a integram.

Provocando o dom da partilha, no propósito de criar os necessários laços de afetividade entre o leitor e o seu texto, J. K. Rowling reforça a integridade da obra através de um diálogo franco e simbólico, forte em estímulos e competências cognoscitivas, capaz de exigir do seu leitor uma reflexão inteligente e assertiva. Sempre apoiada em elementos míticosimbólicos e da realidade pragmática, tal mestria na arte do fazer-perceber enriquece o valor literário de Harry Potter e, a nosso ver, é bem do gosto daqueles que não se prendem exclusivamente às leituras que recusam retratar, na coerência do pragmático-factual, uma realidade que não a nossa. 
O best-seller na revalorização de sentidos: "Harry Potter" e o tema da criança imaginal

Fica-nos, pois, a vontade de também nós subirmos para o carrossel das histórias e (numa atitude de [re]criação) compreendermos as palavras, os sentidos e as ideias que consolidam os emocionantes momentos que vivemos junto dos protagonistas, apostando fortemente no sucesso dos seus empreendimentos, que são metáforas dos grandes mitos da humanidade.

Afastando-nos do conceito das "escolas-fábrica", obstinadamente alicerçadas no desenvolvimento cognitivo da "criança real", que a fazem "cumprir e superar etapas ou fases de crescimento de acordo com modelos pré-estabelecidos que se baseiam [exclusivamente] em saberes científicos" (Araújo \& Araújo, op. cit.), propomos uma reflexão sobre as várias temáticas vigentes nesta saga e que se têm vindo a refletir em obras semelhantes.

Diz Ted Hughes (2002, p. 56) que "a arte de escolher os pequenos detalhes que captam a essência da vida não é tarefa fácil [e que] não se pode tornar viva a existência desse alguém nas palavras somente com a descrição do seu aspeto geral (...)". Acrescentaríamos, à luz do pensamento deste grande poeta britânico, que quando queremos tornar mais vivas e mais presentes as sensações através da palavra escrita, falada, apreendida, não há dúvida de que a palavra partilha é aquela que se destaca das demais. A partilha na configuração do respeito, da sensibilidade, do afeto, do cativar, da entrega, do saber, do conhecer, enfim, do tudo o que faz ser-se alguém desde que se é criança e, sobretudo, quando já não se é criança, mas ainda não se é adulto.

Ora, é do conhecimento comum que os mitos, na Antiguidade, eram usados para ensinar aos jovens valores e condutas éticas que os ajudavam a entender melhor a mensagem veiculada pela narração desses relatos a que tinham acesso. Não queremos aqui dar voz a ensinamentos demagógicos ou reerguer a hegemonia puramente didática do texto de potencial receção juvenil. Trata-se, apenas, de referir a importância do imaginário e do seu estudo na aquisição de competências sociais ou respostas às dúvidas mais comuns das nossas crianças, pré-adolescentes e adolescentes.

A partir de um estudo desta saga numa leitura recreativa de discussão, por exemplo, várias seriam as temáticas a considerar. Tomaremos, contudo, e a título de exemplo, apenas três: a temática da pluralidade social; da dimensão humanitária e social; do espaço identitário 
e da prática do mal, que aborda várias dimensões. A temática da pluralidade social compreende as noções da descriminação, da recriminação, da cidadania, da autoestima, e leva o leitor reflexivo à perceção das imagens da liberdade, da solidariedade, da ética e do humanitarismo, bem como da desigualdade (dimensão humanitária e social). Por sua vez, a temática do espaço identitário, abarcando a imagem arquetípica da Terra-Mater como espaço de organização e de harmonia para a humanidade, remete, de imediato, para as noçôes da partilha, da coletividade, do dever e da consciencialização dos nossos atos no afeto ao Outro. Por último, a temática da autoconsciencialização contra valores negativos (do mal) remete-nos logo para a divisão da humanidade em duas partes distintas: a dos maus e a dos bons, e sabemos que, na maioria destas narrativas, esta é uma das temáticas mais trabalhadas. Ora esta tomada de consciência mostra-nos que a noção da imutabilidade está totalmente enraizada nas façanhas quer dos bons, quer dos maus, e que as imagens da solidariedade, do perdão, da (entre)-ajuda, do amor, da esperança, da coragem, entre muitas outras, devem prevalecer sobre as que lhes são claramente opostas. As noçôes da coragem e do empreendimento, da honra, da demanda e da iniciação, presentes nestas literaturas de reaproximação mítico-simbólica da "nova literatura", permitem a leitura de mitos como o do herói iniciado que, muitas vezes, desce ao abismo (sofre para se fortificar) para enfrentar as forças do mal (no desejo da reposição da ordem cósmica), ou ainda do herói redentor, que consegue transformar-se num exemplo para os outros (Campbell, 2004).

Estas narrativas, algumas até de pendor filosófico, presentificam, através de várias indicaçôes imagéticas, estes ou outros mitos passíveis de uma leitura simbólica, cujo estatuto de diferenciação, relativamente ao domínio da compreensão de valores humanos fundamentais, sociais e culturais, se prende com esta outra forma de ler. Fazer uso do imaginário para enriquecer ao nível da simbolística as competências inerentes aos currículos de cada disciplina seria, a nosso ver, uma vitória na conquista de leitores reflexivos e competentes. Defendemos ainda que, se as aulas, contribuindo para o crescimento do indivíduo como sujeito em iniciação no difícil processo da sua individualização, fossem espaços de abertura às suas demandas (individual e coletiva), o sujeitoleitor e aluno seria um Eu interessado em debater temáticas deste género, inquestionavelmente enriquecedoras para a sua formação como ser imaginal e cidadão responsável. 
No fomento de uma interdisciplinaridade construtiva, várias são as disciplinas do saber que podem usufruir desta sabedoria ancestral e cativar os leitores como indivíduos de uma mesma comunidade escolar e social, na exploração de símbolos, imagens e temas que podem ajudar em uma melhor compreensão/motivação para a vida. Ao leitor criativo, coautor dos textos que lê, cabe pôr mãos à obra e detetar similitudes entre as imagens e negá-las ou aceitá-las como entidades de revalorização sistemática no treino da sua participação como sujeito ativo. Ao docente mediador cabe contribuir na divulgação das plurimensagens pela seleção de textos literários que apelem à cooperação interpretativa do discenteleitor. Isto é, devemos saber "construir um lago de água pura e cristalina (leia-se a personalidade do educando) e encontrar a fonte original de uma água transparente e fresca (leia-se os interesses naturais da criança)" (Araújo, 2004, p. 84) ou do adolescente, no nosso caso.

Contestamos, portanto, atitudes que invalidem a capacidade imaginativa da criança ou do adolescente, pois os símbolos e as imagens são partes constituintes do cosmos no qual o indivíduo realiza as suas manifestações sociobiológicas, socioafectivas e socioculturais, destacando-se como homo-symbolicus que é. Logo, o espaço da imaginação nada mais é do que um espaço de excelência para as suas constantes tentativas de interpretação do mundo.

\section{Conclusão}

Harry Potter foi, sem dúvida, a obra que reergueu, aos olhos das comunidades interpretativas dos leitores mais jovens (pré-adolescentes e adolescentes), temáticas isoladas e mesmo nunca exploradas. Consideramos, convictos, que também são estes textos que enriquecem o seu conhecimento enciclopédico e a sua criatividade linguística, estética e semântica. São, de facto, eles que propiciam, se não grandes metáforas e imagens poéticas (facilmente identificadas nos textos canónicos), verdadeiras emoções e sensações, ${ }^{9}$ e é através da prática de leitura desta "nova literatura" juvenil que o jovem leitor conseguirá aceder ao patamar do "leitor" reconhecido como tal. Desta feita, este somará sempre outras experiências às suas, para, de seguida, aceder com gosto a outras leituras, a canónica (institucionalizada na escola), por exemplo, entusiasmando-se e aprendendo com ela. Se, efetivamente, podemos fazer 
desta "nova literatura" (de qualidade literária) um trampolim para saltos mais ágeis, realizados com segurança e prazer, consideramos ser viável e necessário destacá-la das demais obras da literatura juvenil e reverenciá-la, por angariar leitores promissores.

Finda a nossa exposição, gostaríamos de reafirmar, em forma de apelo, que só um estudo da literatura, baseado nos princípios da teoria da literatura em contínua concomitância com o estudo da hermenêutica do imaginário (em contexto académico, escolar e familiar), permitirá reconhecer o predomínio de temas, imagens e símbolos que esta "nova literatura” alberga. Só assim o ato leitor poderá ser entendido pelos mais jovens como uma "mais-valia" capaz de lhes oferecer momentos de ensino/aprendizagem balizados na descoberta. E só assim também, julgamos, se poderá construir o verdadeiro Ser-leitor imaginal, que será o portador de qualidades e reminiscências arquetipais das quais partilhou em diálogos polifónicos, interdisciplinaridades e transversalidades de ideologias, conteúdos e valores.

Compreender a obra literária infanto-juvenil contemporânea, de caráter mítico-simbólico, como um veículo de partilha de conhecimentos, de valores e de mensagens plurais (na promoção da leitura e da escrita e na divulgação de uma literacia do imaginário) foi e sempre será a militância daqueles que ousam levar a bom porto o ato da leitura como um dos mais nobres na compreensão do Eu e do seu circundante.

\section{Notas}

1. Relativamente à produção literária juvenil, destacamos esta "nova literatura” na medida em que ela se viabiliza nas preferências dos adolescentes ou pré-adolescentes, sendo ela o exemplo actual do fenómeno de anexação dos jovens leitores, configurando a noção de "Modern Fantasy" (cf. Le Guin, 1979; Huck, Hepler \& Hickman, 1993; Cullinan \& Galda, 1994). Dado que esta "nova literatura" integra o fantástico, género permissivo à elaboração de livros de pouca ou nenhuma qualidade literária (e que, infelizmente, pululam no mercado livreiro), salientamos que nesta "nova literatura" apenas distinguimos os livros de carácter literário, relegando para o plano do não literário os livros castradores e limitadores ao nível da novidade semiótica, pois são incapazes de proporcionar momentos de experiências estéticas com o seu leitor, incapacitando-o ainda de reforçar as suas competências enciclopédica e linguística.

2. Entendemos "literatura" como um conceito amplo que, no caso da literatura infantil ou juvenil, se define como um "Conjunto de obras que se particularizam e ganham feição especial quer pela sua origem, quer pela sua temática ou pela sua intenção (...)” (Aguiar \& Silva, 1998, p. 7). 
3. Face às noçôes de "literatura infantil" e "literatura infanto-juvenil", consideramos para os nossos trabalhos a noção de "literatura de potencial recepção infantil" (Azevedo, 2006, p. 12), na medida em que entendemos ser aquela que lhe atribui uma maior especificidade por ser mais abrangente e adequada na distinção das demais literaturas (para adultos; "literatura para a infância" e ainda para jovens); sobretudo porque concordamos com o que Azevedo (op. cit.) refere relativamente à semanticidade atribuída ao atributo "infantil", mais ainda se pensarmos na literatura destinada aos adolescentes, a dita "juvenil".

4. Algumas narrativas ou romances jovens da "nova literatura" de qualidade literária estão no limiar entre o fantástico e o maravilhoso, como é o caso da obra $A$ lenda de Despereaux, de Kate DiCamillo, por exemplo.

5. Dado que, no Reino Unido e alguns estados da América, este género literário é um género de eleição há já muitas décadas, sobretudo para os pré-adolescentes e adolescentes, estudiosos na área da literatura infantil e juvenil diferenciaram, dentro da "Modern Fantasy", o que se deve entender por "High Fantasy" e "Normal Fantasy".

6. Só para citar, a nosso ver, os mais exemplificativos referimos os estudos de Carl Gustav Jung (1993), de Maria Montessori (1996; 2000), de Filipe Alberto Araújo (2004; 2007; 2008) e Joaquim Machado Araújo (2007; 2008).

7. Segundo os autores citados, "o educador, enquanto conselheiro, é um padogogos que faz do educere (conduzir para fora, levar de dentro para fora), e não do educare (alimentar de fora), o seu lema principal de acção" (2008).

8. O mito do herói ou o monomito (Campbell, 2004) encontra-se perpetuado na literatura através da dinâmica da mitocrítica sempre que a personagem principal (individual ou colectiva) é afastada do seu ambiente habitual e empreende, levada por um desafio maior, uma viagem no sentido de uma aventura de carácter físico, psicológico ou ambos, no cumprimento da sua missão.

9. Muitas inclusive entusiasmantes na sua forma de ser e que, muitas vezes, não se destacam em determinados textos canónicos, não porque não existam de facto, mas porque os adolescentes já não vibram com elas.

\section{Referências}

AGUIAR, V.M. Teoria da literatura. Coimbra: Almedina,1998.

ARAÚJO, A.F. Educação e imaginário. Da criança mítica às imagens da infância. Maia: Ismai, 2004.

ARAÚJO, A.F.; ARAÚJO, J.M. Figuras do imaginário educacional. Lisboa: Instituto Piaget, 2004.

ARAÚJO, A.F.; ARAÚJO, J.M. Da criança simbólica às imagens míticas da infância. In: F. Azevedo et al. (Org.). Imaginário, identidades e margens - Estudos em torno da literatura infanto-juvenil. V.N. de Gaia: Gailivro, 2007. p. 15-34. 
ARAÚJO, A.F.; ARAÚJO, J.M. Da criança real e da infância imaginal. Desafios para a pedagogia. In: CONGRESSO INTERNACIONAL EM ESTUDOS DA CRIANÇA, INFÂNCIAS POSSÍVEIS E MUNDOS REAIS, 1., Actas... 2 a 4 fev. 2008. Braga: Universidade do Minho, 2008. (CD-ROM)

AZEVEDO, F. Texto literário e ensino da língua. A escrita surrealista de Mário Cesariny. Braga: Centro de Estudos Humanísticos, Universidade do Minho, 2002.

AZEVEDO, F. Literatura infantil - recepção leitora e competência literária. In: AZEVEDO, F. (Coord.), Lingua materna e literatura infantil - elementos nucleares para professores do ensino básico. Lisboa: Lidel, 2006. p. 21.

CAMPBELL, J. El héros de las mil caras. Psicoanálisis del mito. Madrid: Fondo de Cultura Economica de España, 2004.

CULLINAN, E.B.; GALDA, L. Literature and the child. 3. ed. Orlando: Harcourt Brace, 1994. p. 201-212

DURAND, G. Le retour des immortels. Structures et procédures de l'immortalisation dans le roman de Proust, de Thomas Mann et de Faulkner. In: PONTALIS, J.B. (Dir.). le temps de la réflexion. Paris: Gallimard, 1982. p. 203-299.

ECO, U. Apontamentos sobre a semiótica da recepção. In: Eco, U. Os limites da interpretação. Lisboa: Difel, 1990.

ELIADE, M. Images et symboles. Paris: Gallimard, 1999.

ELIADE, M. Le mythe de l'éternel retour. Paris: Gallimard, 2001.

HUGHES, T. O fazer da poesia. Lisboa: Assírium \& Alvim, 2002.

ISER, W. L'acte de lecture. Théorie de l'effet esthétique. Belgique: Mardaga, 1997.

JUNG, C.G. Contribution à la psychologie de l'archétype de l'enfant. In: JUNG, C.G. ; KERÉNYI, K. Introduction à l'essence de la mythologie. Paris: Payot, 1993. p. 105-144.

LE GUIN, U.K. National Book Award Acceptance Speech. In: 
O best-seller na revalorização de sentidos: "Harry Potter" e o tema da criança imaginal

WOOD, S. (Coord.). The language of night: essays on fantasy and science fiction. New York: Putman,1979, p. 58.

MONTESSORI, M. L'éducation et la paix. Paris: Desclée de Brouwer, 1996.

MONTESSORI, M. Educazione per un mondo nuovo. Milano: Garzanti, 2000 .

RIFFATERRE, M. La production du texte. Paris: Édition du Seuil, 1979.

SARTRE, J.-P. L'imaginaire, psychologie phénoménologie de l'imagination. Paris: Gallimard, 1992.

SILVA, G. Iniciação e demanda - um estudo mitocrítico no domínio da literatura infanto-juvenil : Harry Potter e a pedra filosofal e $A$ ilha do chiffre de ouro no contributo de uma literacia do imaginário. Braga: Universidade do Minho, 2006.

SILVA, G. Literatura infanto-juvenil contemporânea: J. K. Rowling, Isabel Allende e Christopher Paolini numa reaproximação mítico-simbólica. In: AZEVEDO, F. et al. (Org.). Imaginário, identidades e margens - estudos em torno da literatura infanto-juvenil. V.N. de Gaia: Gailivro, 2007. p. 247-261.

SLOAN, G.D. The child as critic: teaching literature in elementary and middle schools. 3. ed. New York: Teachers College Press, 1991.

VIERNE, S. Rites, Roman initiation. Grenoble: Presse Universitaire de Grenoble, 2000.

YOPP, H.K.; YOPP, R.H. Littérature-based reading activities. 3. ed. Plymouth: Allyn and Bacon, 2001.

Recebido em 10 de junho de 2009.

Aprovado em 20 de novembro de 2011. 